IOSR Journal of Pharmacy

ISSN: 2250-3013, www.iosrphr.org

||| Volume 2 Issue 5 ||| Sep-Oct. 2012 || || PP.19-22

\title{
Expression of flak flagellin from Salmonella Typhimurium in tobacco seeds
}

\author{
Luciana Rossi ${ }^{1 *}$, Antonella Baldi ${ }^{2}$, Vittorio Dell'Orto ${ }^{3}$, \\ Serena Reggi ${ }^{4}$, Corrado Fogher ${ }^{5}$ \\ ${ }^{\text {I}(U n i v e r s i t a ̀ ~ d i ~ M i l a n o, ~ D e p a r t m e n t ~ o f ~ V e t e r i n a r y ~ S c i e n c e s ~ a n d ~ T e c h n o l o g y ~ f o r ~ F o o d ~ S a f e t y, ~}$ \\ Via Celoria, 10, 20134 Milan, Italy; \\ ${ }^{2}$ (Università di Milano, Department of Veterinary Sciences and Technology for Food Safety, \\ Via Trentacoste 2, 20133 Milan, Italy; \\ ${ }_{3}^{3}$ (Università di Milano, Department of Veterinary Sciences and Technology for Food Safety, \\ Via Celoria, 10, 20134 Milan, Italy; \\ ${ }^{4}$ (Plantechno S.r.l. Via Staffolo, 60; 26040 Vicomoscano, Cremona, Italy; \\ ${ }_{5}^{5}$ Catholic University. Institute of Agronomy, Genetics and Field Crops. Via Emilia Parmense, \\ 84. 29100 Piacenza, Italy;
}

\begin{abstract}
In the epidemiology of Salmonella Typhimurium, recognized as major zoonotic pathogens of animals and humans, swine plays an reservoir role. Novel methods are requires to control salmonellosis in livestock, and vaccination represent an efficacious way to prevent the disease, reducing antibiotic treatments, as suggested by EC Regulation 1831/2003. In this contest plants have considerable potential and represent a promising alternative for biopharmaceutical protein (plant-vaccine). For these reasons the aim of this study was to engineer tobacco plants in order to induce the seed specific expression with correct folding of flgK protein from Salmonella typhimurium for the subsequent utilization as edible vaccine or as an advantageous system of production. flgK gene was isolated by a polymerase chain reaction (PCR) from a wild type Salmonella typhimurium strain, and transferred into a expression cassettes under control of seed-specific GLOB promoter in order to induce, after agroinfection, the expression of flgK in seeds. Transformed plants showed a correct transcription of flgK gene and the estimated amount of expressed flgk was about $0.6 \mathrm{mg}$ per gram of seeds corresponding to $0.3 \%$ of the total soluble protein. In conclusion our data showed flgK flagellin could be expressed in tobacco seeds and stably incorporated into plant genoma.
\end{abstract}

Keywords-Salmonella typhimurium, flagella, flgk, antigens, tobacco seeds, plant-vaccine

\section{INTRODUCTION}

Salmonella Typhimurium strains are recognized as major zoonotic pathogens of animals and humans and can be found in a broad range of species as well as the environment [1]. The most frequently isolated Salmonella serotypes from pigs is $S$. thyphimurium In particular in swine salmonellosis are serious problem responsible for enterocolites of variable severity followed by a carrier state that can last up to 28 week [2,3]. This status establishes the maintenance of the infection in the involved farms, causing eminent economic losses for intensive livestock farming, and represents an important public health risk [4]. Swine represent reservoir for human infections [5]. In fact according to scientific report of EFSA the prevalence of Salmonella-positive slaughter pigs was up to $10.3 \%$, although with variation among Member States, including both primary infections and surface contamination of carcasses. Novel methods are requires to control salmonellosis in livestock, and vaccination represent an efficacious way to prevent the disease. An efficient vaccination strategy may to reduce antibiotic treatments, as suggested by EC Regulation 1831/2003.

In this contest the use of transgenic plants as bioreactor for the production of vaccine antigens or as delivery system for vaccine proteins is attractive for its simplicity and increases likelihood for local immune response at sites of infection. Plants have considerable potential and represent a promising alternative for biopharmaceutical protein production [6,7]. Plant-based vaccines offer a new approach to vaccination strategies especially to prevent infection by enteric pathogens. Transgenic plant seeds can be suited for the targeted synthesis of heterologous proteins and offer many advantages, such as a lower risk of contamination than vaccines produced by pathogenic organism and, when fully developed, a simple, inexpensive scale-up for the commercial production [8]. In this study the attention was focalized on flgK flagellin, an hook-filament 
junction protein, of Salmonella typhimurium and an important virulence factor that contribute to intestinal inflammation [9]. Nonflagellated serotype Typhimurium mutants have been shown to cause less inflammation than their isogenic parents do after infection of bovine ligated ileal loops [10]. Moreover flagella have a pivotal role in motility and invasion of mucosal surface. For these reasons the aim of this study was to engineer tobacco plants in order to induce the seed specific expression with correct folding of flgK protein of Salmonella typhimurium for the subsequent utilization as edible vaccine or as an advantageous system of production of proteic antigens.

\section{MATERIAL AND METHODS}

\subsection{Transferring of flgK wild type gene into plant genoma by agroinfection}

The gene encoding for flgK was isolated by a polymerase chain reaction (PCR: 25 cycles of 1 min of denaturation at $94^{\circ} \mathrm{C}, 1^{\prime} 20^{\prime \prime}$ of annealing at $55^{\circ} \mathrm{C}$, and $1^{\prime} 30^{\prime \prime}$ of extension at $72^{\circ} \mathrm{C}$ ), from genomic DNA purified from a liquid culture of a wild type Salmonella typhimurium isolated from a piglets dead for salmonellosis. Oligonucleotide primers, including unique cloning sites for specific endonucleases (BamH I- 5', Sac I-3'), were used to facilitate direct subcloning of the fragments in the plant transformation vector. The amplified flgK gene, purified from agarose gel (Geneclean, Q-Bio Gene, Montreal, Canada), were inserted into a high copy number plasmid vector (pGEM-T easy, Promega, Italy) and used for XL1B E. coli strain transformation by electroporation. Preliminary clones selection was performed by restriction analysis, followed by DNA sequencing. DNA SacI-BamHI fragment, obtained by digestion of pGEM-T-flgK, was separately subcloned in a pBI-GLOB vector (Patent WO0004146). GLOB is the soybean basic 7S globulin promoter (DDBJ accession no. AX006477) and it was used for the seed-specific expression of antigenic proteins according to Reggi et al. [11]. The chimeric constructs pBIpGLOB-flgK was used to transform Agrobacterium tumefaciens strain EHA105 by electroporation. For infection of 100 tobacco leaf disks with recombinant Agrobacterium, we used an overnight culture of bacterium whose optical density at $600 \mathrm{~nm}$ (OD600) was about 0.6. Then we put tobacco leaf disk (Nicotiana tabacum L., cv. Xanthi) on MS10 medium to allowed callus shaping for 2 weeks. Kanamycin incorporated into medium allowed for selection of transformed callus tissue, as previously described by Rossi et al. [12].

\subsection{Evaluation of transformation}

The plants were analyzed for the presence of foreign DNA using internal primers of the flgK sequence by PCR, using, for each sample $80 \mathrm{ng}$ of genomic DNA extracted from young leaves of the regenerated plants as a template, according to the method by Doyle and Doyle [13]. The mRNA was evaluated by Northern blot analysis on the immature seeds (12 days after pollination) of all PCR-positive plants. Northern blot analysis was carried out using DIG-labelled RNA probes hybridized with total RNA extracted with one volume of $50 \mathrm{mM}$ Tris buffer $\mathrm{pH} 7.5$ containing $150 \mathrm{mM} \mathrm{NaCl}, 5 \mathrm{mM}$ ethylendiaminetetracetic acid (EDTA), $1 \%$ sodiumdodecilsolphate (SDS), $150 \mathrm{mM} \mathrm{B-mercaptoethanol} \mathrm{and} \mathrm{one} \mathrm{volume} \mathrm{of} \mathrm{phenol:chloroform} \mathrm{(1:1).}$ Electrophoresis, blotting and hybridization were performed as described previously [14], and the specific RNA detection was performed using CDP-star (Boehringer Mannheim) according to the manufacturer's instructions. The total proteins were extracted from all mature transformed tobacco lines by homogenization with liquid N2 in a mortar and protein extraction with the solubilization buffer $(50 \mathrm{mM}$ Tris, $\mathrm{pH} 8,5 \mathrm{mM}$ EDTA, $200 \mathrm{mM}$ $\mathrm{NaCl}, 0.1 \%$ Tween 20). Protein content was estimated by a Bradford assay (BioRad, Hercules, USA) using bovine serum albumin as the standard. The expression of flgK in the total protein sample was evaluated by Western blotting with specific polyclonal antibodies obtained from New Zealand rabbits, after immunization with flgK expressed through pET-system (Novagen) in BL21 E.coli strain. Samples (80 ug total protein) were loaded in a $10 \%$ polyacrylamide gel together with the Precision Standards (BioRad, Hercules, USA) and a positive control represented by $200 \mathrm{ng}$ of VT2eB protein obtained through pET-system (Novagen) in BL21 E.coli strain. The proteins were transferred to an Immobilon-PSQ membrane (Millipore, Billerica, USA) with the Trans-Blot SD apparatus (BioRad, Hercules, USA); the filters were incubated overnight with rabbit polyclonal anti-VT2e-B serum (1:5000). After incubation for 1 hour with HRP-conjugated secondary antibody $(1: 10,000)$, chemiluminescence was developed using the SuperSignal West Pico Trial Kit (Pierce, Rockford, USA). The positive producing lines, evaluated as previously described, were selected and self-pollinated. The second generation was propagated in a greenhouse to produce the required amount of seed.

\section{RESULTS AND DISCUSSION}

PCR products putatively encoding the flgK were identified on agarose gel $(0,8 \%)$ as bands with a length of 1662 (Fig 1). Since the inserted products showed the expected size in agarose gel, they were recovered from the gel, diafiltrated against water and ligated into plasmid $\mathrm{T}$-vectors for restriction analyses and sequencing. The sequencing results of three clones of flgK and three clones of the VT2e-B subunit demonstrated the full identity of our sequences with the one present in database. Obtained data confirmed the correct insertion 
of genes and the match of the sequence of obtained genes with GenBank. The engineered vectors were used to generate a transgenic population composed of independently kanamycin-resistant transgenic plants, which had a similar morphological appearance to the wild-type plants. About $80 \%$ of lines of transformed tobacco plants, screened for the presence of genes by PCR on DNA from young leaves, were harbouring transgenes. Samples containing transgenes were identified by the presence of an amplified product of $1.6 \mathrm{~Kb}$, representing the gene encoding flgK fimbriae.

Northern blot analyses was performed on tobacco seeds in order to select transcription positive transformants and to verify proper mRNA processing and to estimate RNA abundance, depending on the position effects of the integrated transgene. Northern blot analyses showed signals corresponding to flgK mRNA in the $60 \%$ of the PCR positive flgK plants.

Different lines were compared for transgene transcription and lines with stronger signals than others were selected for subsequent plant generations. Western blot analysis, carried out on all positive for flgK mRNA plants, detected flgK signals in all samples, and by comparision with a positive control (flgK protein expressed by pET system in BL21 Escherichia coli strain) the amount of flgK was estimated about $0.6 \mathrm{mg}$ per gram of seeds corresponding to $0.3 \%$ of the total soluble protein in tobacco seeds. No cross-reacting proteins were identified in any of the wild-type seed extracts. No traces of degradation products were apparent in any of the transformed samples. The best lines of tobacco regenerated plants were selected, propagated in vitro and then grown in a greenhouse.

\section{FIGURES AND TABLES}

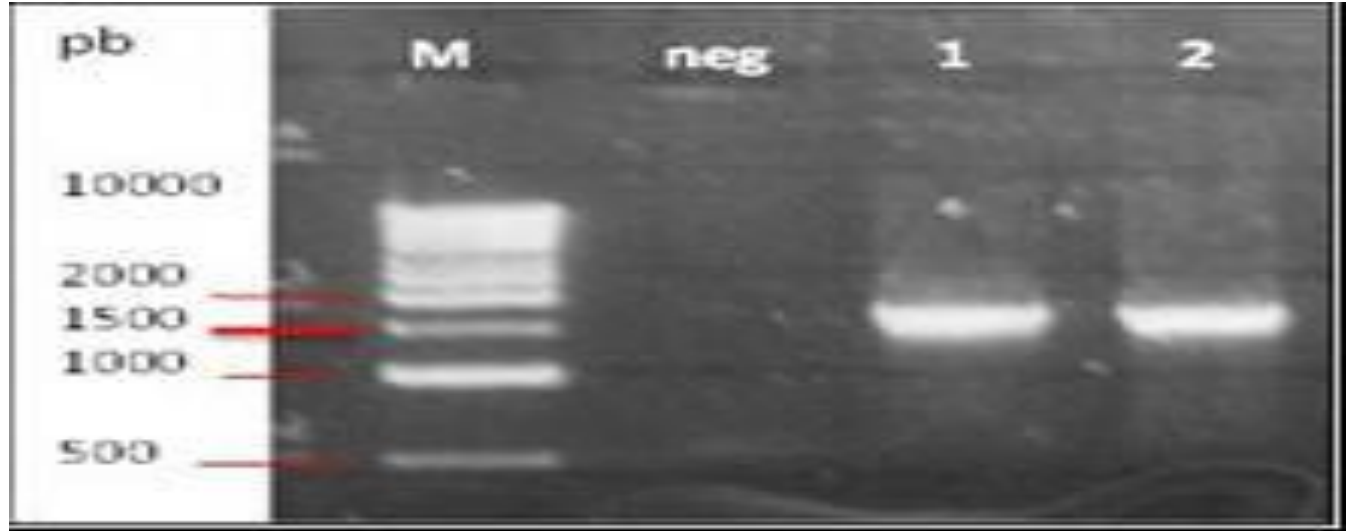

Fig 1: Agarose gel of PCR products for flgK gene (1662pb). M: marker; neg: negative control; 1,2 positive samples

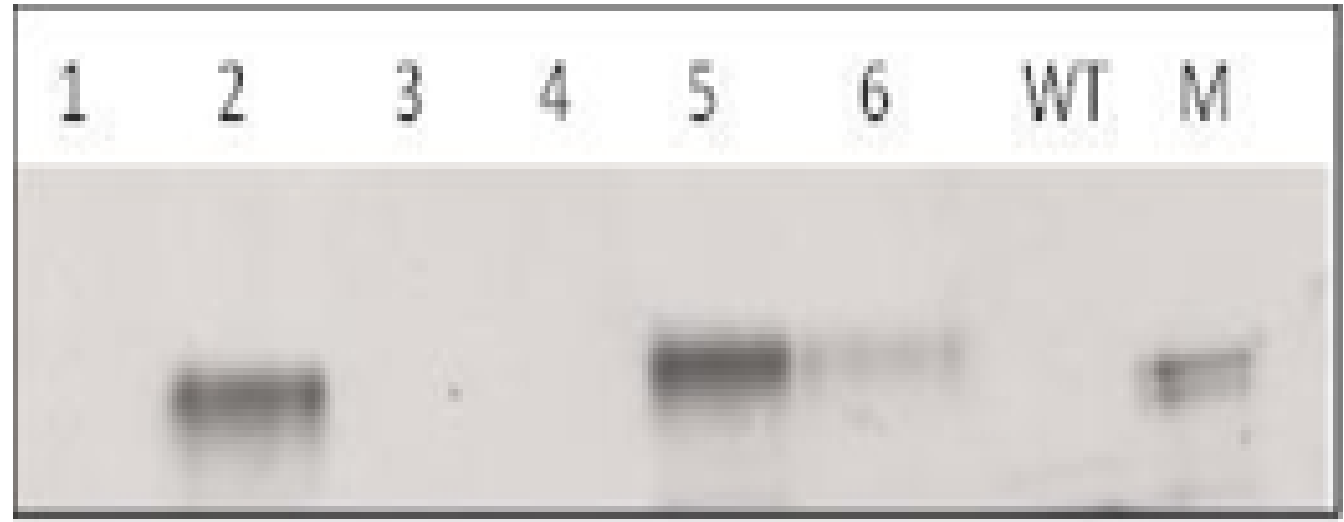

Fig 2: Western blot of flgK. M: positive control represented by $200 \mathrm{ng}$ of flgK expressed throught pET-system in BL21 E.coli strain; lanes 1,3,4: negative samples; lanes 2,5,6: positive samples; WT: wild type.

\section{CONCLUSION}

This study showed that the foreign flgK gene, derived from a wild type Salmonella typhimurium strain, can be stably incorporated into tobacco plant genome by being transcribed through the nuclear apparatus of the plant for specific expression in the seeds, and that these genes are inherited by the next generation. Tobacco seeds could be used as an efficacious system for flgk flagellin expression. 


\section{Examples follow:}

\section{REFERENCES}

[1]. P J Fedorka-Cray, L Collins Kelley, T J. Stabel, J T. Gray, JA Laufer, Alternate Routes of Invasion May Affect Pathogenesis of Salmonella typhimurium in Swine, Infection and Immunity, 63(7), 1995, 2658-2664.

[2]. A Rementeria, AB Vivanco, A Ramirez, FL Hernando, J Bikandi; S Herrera-Leon, A Echeita and J Garaizar, Characterization of monoclonal antibody directed against Salmonella enterica serva Typhimurium and serovar [4,5,12:i-], Applied and Enviromental Microbiology, 75 (5), 2009, 1345-1354.

[3]. WA Gebreyes and C Altier, Molecular Characterization of Multidrug-Resistant Salmonella enteric subsp. enterica Serovar Typhimurium Isolates from Swine, Journal of Clinical Microbiology, 40 (8,) 2002, 2813-2822.

[4]. EFSA Panel on Biological Hazards. Scientific Opinion on monitoring and assessment of the public health risk of "Salmonella Typhimurium-like" strains. EFSA Journal 2010;8(10):1826. [48 pp.]. doi:10.2903/j.efsa.2010.1826. Available online: www.efsa.europa.eu/efsajournal

[5]. N Bergeron, J Corriveau, A Letellier, F Daigle and S Quessy, Characterization of Salmonella Typhimurium isolates associated with septicemia in swine, The Canadian Journal of Veterinary Research , 74, 2010, 11-17

[6]. SJ Streatfield, JM Jilka, EE Hood, DD Turner, MR Bailey, JM Mayor, et al., Plant-based vaccines: unique advantages, Vaccine, 19, 2001, 2742-2748.

[7]. HS Mason, H Warzecha, T Mor and CJ Arntzen. Edible plant vaccines: applications for prophylactic and therapeutic molecular medicine, Trend Molecular Medicine, 8 (7), 2002, 324-329.

[8]. R Fischer, E Stoger, S Schillberg, P Christou and RM Twyman, Plant-based production of biopharmaceuticals, Current opinion in Plant Biololy, 7, 2004, 152-158.

[9]. SE Winter, P Thiennimitr, SP Nuccio, T Henry, QT Tran, SD Lawhon, G Gomez, C Bevin, H Russman, DM Monack, LG Adams and AJ Baumler, Contribution of flagellin pattern recognition to intestinal inflammation during Salmonella enteric serotype typhimurium infection, Infection and Immunity, 77(5), 2009, 1904-1916.

[10]. RM Macnab, How Bacteria assemble flagella, Annual review Microbiological, 57, 2003, 77-100.

[11]. S Reggi, S Marchetti, T Patti, F De Amicis, R Cariati, B Bembi and C Fogher. Recombinant human acid $\beta$ glucosidase stored in tobacco seed is stable, active and taken up by human fibroblasts. Plant Moecular Biololy, 57, 2005, 101-113.

[12]. L Rossi, A Baldi, V Dell'Orto and C Fogher, Antigenic recombinant proteins expressed in tabacco seeds as a model for edible vaccines against swine oedema, Veterinary Research Communication, 27 (s1), 2003, 659-661.

[13]. JJ Doyle, J L Doyle, A rapid DNA isolation procedure for small quantities of fresh leaf tissue. Phytochemical Bulletin, 19, 1987, 11-15.

[14]. J Sambrook, DW Russell. In: Molecular Cloning: A Laboratory Manual. Third Edition, Argentine editor. Cold Spring Harbour Laboratory Press, Cold Spring Harbour, New York, Harbor Laboratory Press, 2001, 731-744. 